\title{
Iron Deficiency Anemia
}

\author{
$\mathrm{Na}$ Hee Lee \\ Department of Pediatrics, Cha Bundang Medical Center, Cha University, Seongnam, Korea
}

\begin{abstract}
Iron deficiency anemia (IDA) is a common medical problem that affects an estimated $30-50 \%$ of the world's population. The causes of IDA are malnutrition, rapid growth with improper dietary iron, blood loss through gastrointestinal tract or menstruation. The genetic factors of iron-refractory iron deficiency anemia have also been identified. Previous studies on the theory of hepcidin-based homeostatic regulation have helped increase our understanding of iron metabolism. Symptoms of anemia may include non-specific symptoms, such as pale appearance, fatigue, weakness, and decreased appetite, as well as impaired neurocognitive functions, including delay mental development and restless leg syndrome. IDA can be diagnosed by laboratory findings. The conventional tests that are typically performed to diagnose IDA include hemoglobin level, serum iron, transferrin saturation, and ferritin level, as well as soluble transferrin receptor, hepcidin level, zinc protoporphyrin, reticulocyte hemoglobin content. Treatment begins with an accurate diagnosis, and both oral and parenteral iron can be used. Symptoms improve quickly after treatment; however, the diagnosis and treatment of IDA is rather overlooked. Therefore, it is necessary to better understand the disease process of IDA, make an accurate diagnosis, and prescribe essential iron supplements to patients with symptoms.
\end{abstract}

Key Words: Iron deficiency, Anemia, Hepcidin
pISSN 2233-5250 / eISSN 2233-4580 https://doi.org/10.15264/cpho.2020.27.2.101 Clin Pediatr Hematol Oncol 2020;27:101 112

Received on August 12, 2020 Revised on September 17, 2020 Accepted on September 24, 2020

Corresponding Author: Na Hee Lee Department of Pediatrics, Cha Bundang Medical Center, Cha University, 59 Yatap-ro,

Bundang-gu, Seongnam 13496, Korea

Tel: +82-31-780-5230

Fax: +82-31-780-5239

E-mail: nangs@hanmail.net

ORCID ID: orcid.org/0000-0002-2569-4016

\section{Introduction}

Iron deficiency (ID) and Iron deficiency anemia (IDA) are common medical problems worldwide. ID is a type of malnutrition, while IDA is the top cause of anemia [1]. It is estimated that $30-50 \%$ of the global population has IDA and the prevalence of ID worldwide is twice as high as that of IDA [2,3]. The prevalence is now highest in Central and West Africa and South Asia, particularly 58\% and $71 \%$ in children younger than 5 years, respectively $[1,4]$. In a systematic analysis for the Global Burden of Disease Study 2017, ID was globally the leading Level 3 cause of years lived with disability for all ages and both sexes [5]. In the 2014 domestic report based on the Korea National Health and Nutrition Examination Survey, prevalence of ID was $2.0 \%$ for men and $22.4 \%$ for women, and the prevalence of IDA was $0.7 \%$ for men and $8.0 \%$ for women [6]. In particular, IDA is known to occur in early childhood, which is a period of rapid growth, and in adolescents during active growth [7]. Recently, IDA of infants and toddlers is decreasing due to improved nutrition and awareness. However, IDA of adolescence is increasing due to weight loss which is influenced by the social pressures, especially for girls who have increased iron loss from menstruation.

It is necessary to have a clear understanding of iron metabolism, as well as the various causes of IDA in order 
to treat IDA appropriately.

\section{Iron Metabolism}

Normal adults have about 3-5 g of iron in their bodies, in which 60\% is stored in hemoglobin, 10\% in myoglobin, and the other $30 \%$ in hepatocytes and reticulocytes [8]. More than 200 billion red blood cells are produced per day. This requires $20-25 \mathrm{mg}$ of iron, most of which is obtained from senescent erythrocytes stored in reticuloendothelial macrophages, while 1-2 mg of iron is absorbed by small intestinal epithelial cells in the duodenum (Fig. 1A) [8].

Iron availability is tightly regulated at both the cellular and systemic levels through coordination to the expression of iron importer and exporter, and storage of iron [9]. This mechanism is regulated by hepcidin-based homeostatic controls [10]. Hepcidin is a small peptide hormone that is mainly synthesized in the liver and was first described in 2001 in mice with iron overload [11,12]. A major role of hepcidin is preventing iron released into plasma from enterocyte or macrophage stores. This is due to hepcidin binding to ferroportin (FPN), an iron-exporting protein, to form lysosomes, and is subsequently internalized and degraded (Fig. 1B) [8,12]. The expression of hepcidin is up-regulated by high concentrations of iron in the plasma and liver, inflammation cytokines, and physical activity (Fig. 1B) [13].

Alternatively, hepcidin expression is down-regulated by expansion of erythropoiesis, tissue hypoxia and ID (Fig. 1C) [9,10]. Several mechanisms are involved in downregulation of hepcidin expression. In the hepatocyte, the bone morphogenic protein (BMP)-SMAD signaling pathway is repressed, since low levels of BMP6, the main activator of hepcidin, are produced by liver sinusoidal endothelial cells [14-17]. This process is regulated by neogenin (NEO1) and transmembrane serine protease 6 (TMPRSS6). NEO1 regulates the expression of hepcidin by stabilization of hemojuvelin (HJV), a co-receptor of BMP [18]. TMPRSS6 disrupts the synthesis of hepcidin by cleaved HJV [19]. Hepcidin is also regulated by histone deacetylase 3 , erasing markers of activation at the hepci- din locus [20]. Additionally, increased erythroferrin due to hypoxia participates in hepcidin suppression; however, the exact mechanism is still unknown [21].

Therefore, transcription of hepcidin is decreased in ID results in increased intestinal iron uptake from the gut lumen via divalent metal transporter 1 , and iron uptake by enterocytes is actively exported to circulation. Also, macrophages rapidly recycle iron derived from phagocytosis of senescent red cells (Fig. 1C). There is also an increase in iron release by hepatocytes; however, release is slower than observed in macrophages, which are thought to be a long-term reservoir of iron [3].

\section{Causes of Iron-Deficiency}

\section{1) Physiologic individuals risk factors}

Absorption of less iron than the body needs is a risk factor for IDA. According to the 2018 National Health Statistics in Korea, the average daily intake of iron in individuals over 1 year of age was $11.6 \mathrm{mg}$; however, in $36.1 \%$ of the population, it was below the standard of intake of iron [22]. In infant and preschool children $(<5$ years of age), rapid growth consumes the iron stores that were absorbed from the mother during gestation, leading to ID. Indeed, low birth weight, prematurity, consumption of cow's milk before 12 months, and breastfeeding alone without additional iron supply after 6months of age are high risk factors for IDA in children $<5$ years of age [2,23]. Adolescents, especially girls, are also at a particularly high risk of ID due to rapid growth and menstrual iron losses. Pregnant and postpartum women are also included in the affected group, since iron needs are increased due to the expansion of maternal red cell mass and the growth of the fetus during pregnancy [13]. In developed counties, healthy individuals who are strict vegan and vegetarian diets, and regular blood donors may be at increased risk (Table 1) [24].

\section{2) Pathologic conditions}

Among the various abnormalities that cause IDA, blood loss is the most common. Sources of blood loss include the gastrointestinal tract, genitourinary system including 
A

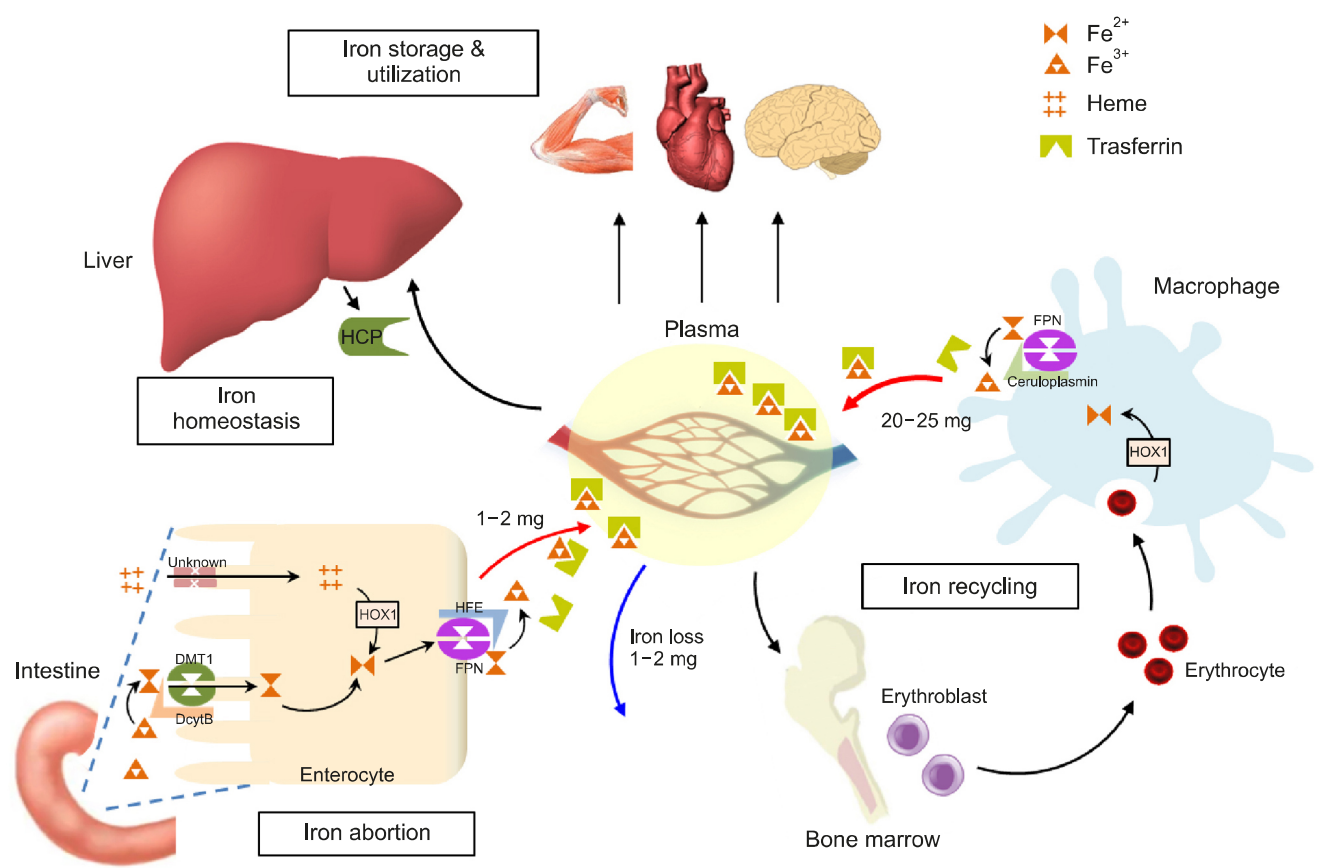

B

C
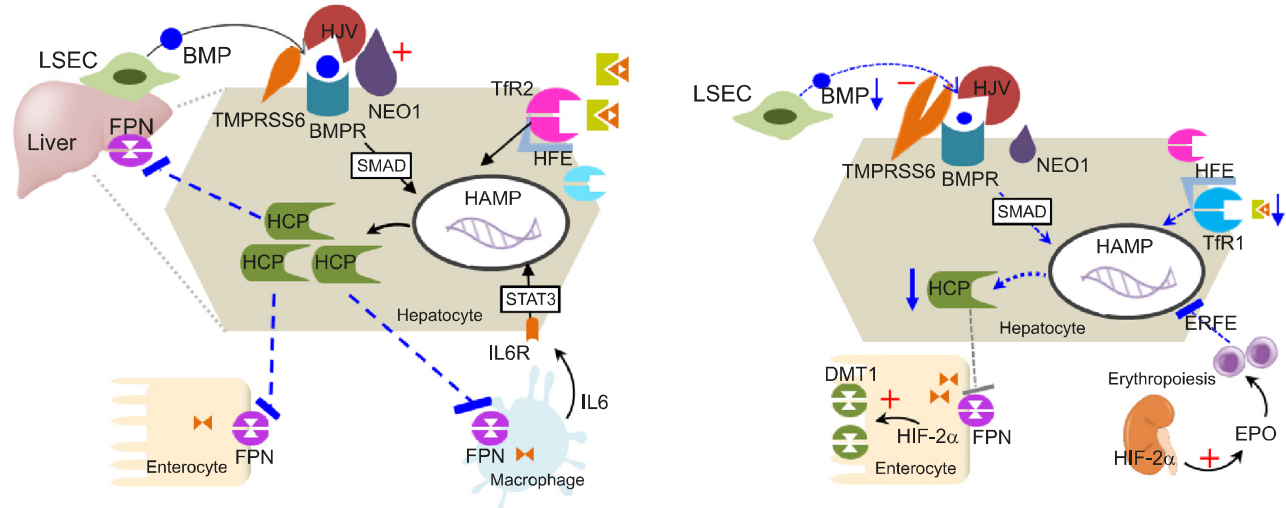

Fig. 1. The iron cycle and adaption to iron deficiency: adapted from reference $[3,8,9,16]$. (A) Iron trafficking: the daily iron requirement is $20-25 \mathrm{mg}$; most iron is recycled from senescent erythrocytes stored in reticuloendothelial macrophage. In addition, 1-2 mg of dietary iron is absorbed by duodenal enterocyte via divalent metal transporter 1 (DMT1) on the apical brush-border membrane after reduction of $\mathrm{Fe}^{3+}$ to $\mathrm{Fe}^{2+}$ through duodenal cytochrome B (DcytB). Although not well known for heme iron, when it enters the intestinal cell by endocytosis, it is released into the cell while being oxidized by heme oxygenase 1 (HOX1). Each cell exports iron through ferroportin (FPN) with the help of hephaestin (HFE) or ceruloplasmin, which convert newly transported $\mathrm{Fe}^{2+}$ to $\mathrm{Fe}^{3+}$. In the plasma, transferrin captures iron and transports it to the organs, which store or utilize iron. Excess iron is also stored in the liver and macrophages as a reserve. (B) Iron homeostasis: in the hepatocytes, bone morphogenic protein (BMP)-SMAD signaling cascade, the main activator of hepcidin, increases hepcidin transcription. BMP6 is produced by liver sinusoidal endothelial cells (LSEC) and neogenin (NEO1) regulates the expression of hepcidin by stabilization of hemojuvelin (HJV), a co-receptor of BMP. In addition, STAT3 signaling induced by the inflammatory cytokine IL6 also increases hepcidin transcription. The HFE, displaced from the transferrin receptor (TfR)1, stabilizes the surface TfR2 to enhance ALK3 signal and increase hepcidin transcription. Subsequently, high concentration of hepcidin binds and degrades FPN in the enterocyte, macrophage, and hepatocyte, blocking iron export. (C) Adaptation to iron deficiency: low levels of BMP6 are produced by LSEC, and HJV is cleaved from the hepatocyte surface by the transmembrane serine protease 6 (TMPRSS6). In addition, iron deficiency induced hypoxia-inducible factor $2 \alpha$ (HIF-2 $\alpha$ ) increases the expression of the DMT1 to increase the transfer of dietary iron, and the production of erythropoietin (EPO) to stimulate erythropoiesis. Increased erythroferrone (ERFE) blocks the hepcidin pathway; however, the molecular mechanism of hepcidin inhibition by ERFE remains unknown. Also, TfR2 is not stabilized on the cell surface in the absence of the ligand diferric transferrin. As a result, low hepcidin levels increase iron absorption by enterocytes and recycling by macrophages through increased activity of the iron exporter FPN. 
Table 1. Cause of iron deficiency anemia $[3,13]$

Cause

Physiologic increased Infant, Pre-school children, Growth spurts in adolescents, Pregnancy, Menstrual blood loss, Blood donation iron demand

Decreased iron intake Poverty and malnutrition, Diet (Iron-poor vegan or vegetarian)

Decreased iron Surgical: Gastrectomy, Duodenal bypass, Bariatric surgery

absorption Medical: H.pylori, Celiac disease, Atrophic gastritis, Inflammatory bowel disease

Cereal-based diet, Proton-pump inhibitors

Chronic blood loss Gastrointestinal tract: Hookworm, Esophagitis, Erosive gastritis, Peptic ulcer, Diverticulitis, Meckel's diverticulum, Benign tumors, Intestinal cancer, Inflammatory bowel disease, Angiodysplasia, Hemorrhoids

Genitourinary tract: Heavy mestural bleeding, Intravascular hemolysis (Paroxysmal nocturnalhemoglobinuria, Autoimmune hemolytic anemias), Familial hematuria (Alport syndrome)

Systemic: Dialysis, Schistosomiasis, Hemorrhagic telangiectasia, Inherited coagulopathies

Drug: Salicylates, NSIAD, corticosteroid, anticoagulants

Inflammation Congestive heart failure, Chronic kidney disease, Inflammatory bowel disease, Obesity

Genetic Iron-refractory iron-deficiency anemia

NSIAD, non-steroidal anti-inflammatory drugs.

intravascular hemolysis, and systemic bleeding (Table 1). Chronic IDA due to occult bleeding in the gastrointestinal tract may reveal the presence of peptic ulcer, Meckel diverticulum, polyp, inflammatory bowel disease, angiodysplasia, or cancer [3]. In developing countries, infections with parasites, such as Necator americanus (hookworm), Trichuris trichiura (whipworm), and Plasmodium, often contribute to IDA [1]. Gynecological blood loss, including heavy menses is the second most frequent cause of IDA [13]. Also, iron is lost in the urine, in rare forms of intravascular hemolysis such as paroxysmal nocturnal hemoglobinuria [3].

Iron is absorbed in the proximal duodenum with the assistance of gastric acid. Accordingly, gastric, or duodenal bypass procedures, Helicobacter pylori (H. pylori) infection, or celiac disease may cause malabsorption of iron [25,26].

Additionally, many drugs can lead to IDA, including non-steroidal anti-inflammatory drugs that increase the chance of blood loss, as well as Proton-pump inhibitors and $\mathrm{H} 2$ receptor antagonist which interfere with iron absorption [13].

IDA due to genetic defect is rare; however, it is important to identify this cause of IDA, since it can result in an ineffective response to oral iron treatment. Anemia can be caused by mutations in genes that control systemic iron homoeostasis (e.g. TMPRSSG), duodenal iron absorption (e.g. SLC11A2), or erythroid iron absorption and utilization [13]. In particular, iron-refractory iron deficiency anemia (IRIDA) is caused by a defect in the TMPRSS6 gene encoding matriptase-2, which plays a key role in the down-regulation of hepcidin [13].

\section{Clinical Findings and Diagnosis}

1) Clinical presentation

IDA is chronic and frequently asymptomatic; thus, it may often go underdiagnosed. The paleness of the skin or conjunctiva is a typical symptom, and when anemia deteriorates, nonspecific symptoms are observed, such as fatigue, weakness, decreased appetite, and irritability. In addition, ID causes decreased cognitive performance and delayed mental and motor development, and it is known that such impairment of neurocognitive function is not completely reversible, even after iron treatment [27]. ID can cause sleep disturbance and restless leg syndrome $[28,29]$. In patients with heart failure, it increased hospitalizations, decreased exercise tolerance, and adversely affected quality of life and survival [30]. Additional related symptoms include pica, koilonychias, and glossitis, which are summarized in the Table 2.

\section{2) Diagnostic investigation}

For diagnosis of IDA, it is important to determine the 
Table 2. Symptoms and signs of iron deficiency anemia [33]

Iron deficiency
Loss of appetite
Fatigue
Irritability/malaise
Hair loss, dry, and damaged hair
Dry and rough skin
Behavioral change
Attention deficit hyperactivity disorder
Restless legs syndrome
Sleep disorder
Pica
Glossitis/decreased papillation of the tongue/burning tongue
Angular cheilitis
Koilonychia/spoon nail
Iron deficiency anemia
Dyspnea on exertion
Pallor
Palpitation
Headaches
Tinnitus
Vertigo
Cardiac murmur
Tachycardia
Heart failure
Syncope

population that should be tested, the diagnostic tests that should be used, and the laboratory threshold that determines whether a patient has IDA [31]. The American Academy of Pediatrics recommends routine screening of IDA at 12 months for all children [32]. However, many experts agree that it is important to screen children or adolescents with symptoms or signs of IDA listed in the Table 2 [33].

As a progress of ID, a sequence of biochemical and hematologic events occurs. First, when the supply of iron is insufficient, there is typically no repercussion by way of reduction of hemoglobin or serum iron. Alternatively, iron depletion state is initially reflected in a decreased level of ferritin, an iron-storage protein. Subsequently, when all the storage iron is consumed, a decrease in serum iron and transferrin saturation occurs, as well as an increase in free erythrocyte protoporphyrin. Then, when ID progresses, microcytic, hypochromic anemia is observed [34]. The means to determine iron status and ID related conditions are presented in Table 3. The gold standard for diagnosis of IDA is Perl's staining of bone

Table 3. Laboratory tests for measurement of iron status [3]

\begin{tabular}{|c|c|c|c|c|c|}
\hline & $\begin{array}{c}\text { Iron } \\
\text { deficiency }\end{array}$ & $\begin{array}{l}\text { Iron } \\
\text { deficiency } \\
\text { anemia }\end{array}$ & IRIDA & $\begin{array}{c}\text { Anemia of } \\
\text { chronic disease }\end{array}$ & $\begin{array}{l}\text { Iron-deficiency } \\
\text { anemia and anemia } \\
\text { of chronic disease }\end{array}$ \\
\hline \multicolumn{6}{|l|}{ Conventional test (normal range) } \\
\hline Iron $(10-30 \mu \mathrm{mol} / \mathrm{L})$ & Low & Low & Low & Low & Low \\
\hline Transferrin saturation (16-45\%) & $\geq 16$ & $<16$ & $<10$ & Low-normal & Low-normal \\
\hline $\begin{array}{l}\text { Hemoglobin } \\
\text { Men }(>13 \mathrm{~g} / \mathrm{dL}) \\
\text { Women }(>12 \mathrm{~g} / \mathrm{dL})^{\mathrm{a})}\end{array}$ & Normal & Low & Low & Low & Low \\
\hline $\begin{array}{l}\text { Ferritin } \\
\text { Men }(40-300 \mu \mathrm{g} / \mathrm{L}) \\
\text { Women }(20-200 \mu \mathrm{g} / \mathrm{L})\end{array}$ & $<30$ & $<10-15$ & Variable & $>100$ & $<100$ \\
\hline Mean corpuscular volume (80-95 fL) & Normal & Low & Very low & Low-normal & Low-normal \\
\hline \multicolumn{6}{|l|}{ New-investigation test } \\
\hline sTFR $(\mathrm{mg} / \mathrm{L})^{\mathrm{b})}$ & High & High & High & Low-normal & Variable \\
\hline sTFR/log ferritin index ${ }^{b}$ & NA & $>2$ & NA & $<1$ & $>2$ \\
\hline Hepcidin $(\mathrm{ng} / \mathrm{mL})^{\mathrm{b})}$ & Usually $\leq 10$ & Very low & Normal-high & High & Normal-high \\
\hline Zinc protoporphyrin $(\mu \mathrm{mol} / \mathrm{mol} \text { heme })^{b)}$ & Normal & High & High & High & High \\
\hline $\begin{array}{l}\text { Reticulocyte hemoglobin content } \\
(31.2 \pm 1.6 \mathrm{pg})\end{array}$ & $<25$ & Low & Low & Low & Low \\
\hline Perl's staining of bone marrow & Negative & Negative & Positive & Strongly positive & Positive \\
\hline
\end{tabular}

IRIDA, iron-refractory iron deficiency anemia; sTFR, Soluble transferrin receptor.

${ }^{\mathrm{a}}$ If, pregnant women $>11 \mathrm{~g} / \mathrm{dL}$. ${ }^{\mathrm{b})}$ Normal values vary according to the method of measurement used. 
marrow for iron; however, it is an invasive procedure and typically not performed [35].

(1) Conventional (first-line) test

Traditional laboratory measurements are used to determine iron status. More specifically, IDA diagnosis is possible by assessing hemoglobin and serum ferritin levels. According to the World Health Organization (WHO), anemia was defined as a hemoglobin level $<13 \mathrm{~g} / \mathrm{dL}$ in men, $<12 \mathrm{~g} / \mathrm{dL}$ in nonpregnant women, and the specific threshold according to the age of child as presented in Table 4 [36]. Serum ferritin level is the most sensitive and specific test for ID, in which a value of $<12-15 \mu \mathrm{g} / \mathrm{L}$ confirms ID [36]. Recently, a value of $<30 \mu \mathrm{g} / \mathrm{L}$ is more widely used, associated with a sensitivity of $92 \%$ and specificity of 98\% [31]. However, interpretation of ferritin levels requires caution in the presence of inflammation.

Serum iron and transferrin saturation (TFs) levels provide a measure of iron available for erythropoiesis. A TFs level $<16 \%$ is commonly used to diagnosis IDA, and it is considered to be suitable even for a level of $<20 \%$ in the presence of inflammation [31]. Red cell indices on full blood counts might show reduced mean cell hemoglobin and mean cell volume, as well as increased red cell distribution width.

\section{(2) Newly investigation (second-line) test}

Soluble transferrin receptor (sTfR) and its relationship to ferritin (sTfR/logft index): Transferrin receptor is cleaved by membrane protease in erythroid cells when it is not stabilized by differic transferrin. Therefore, sTfR levels are increased in ID, as well as during enhanced erythropoietin activity [37]. Consequently, levels can be in- creased in hemolytic anemia or other conditions that increase red cell mass [38]. However, sTfR is not affected by the acute-phase response. Accordingly, its level is useful for differential diagnosis of ID and anemia of chronic disease (ACD). Also, the ratio of sTfR and log ferritin levels help diagnose IDA in ACD, and it is the most useful test in these settings (Table 3) [39]. Unfortunately, cutoff values vary with assay, and based on patient's age and ethnic origin [38].

Hepcidin: Serum hepcidin level is a promising novel biomarker, and it is decreased or undetectable in IDA [40]. Conversely, it is extremely elevated in anemia of inflammation. Serum hepcidin level is affected by liver and kidney function, as well as by the circadian rhythm and should, therefore, be tested early in the morning [40]. Additionally, it is helpful to confirm IRIDA, since serum hepcidin levels are constitutionally high or normal in the presence of this disease. Indeed, it can serve as an alternative to performing the TMPRSS6 gene sequencing test in IRIDA [35].

Zinc protoporphyrin (ZPP): Erythrocyte ZPP is a product of abnormal heme synthesis. In the case of ID, zinc transport through the intestinal barrier is increased [13]. Thus, the concentration of ZPP in erythrocyte is increased over 70-80 $\mu \mathrm{g} / \mathrm{dL}$ in IDA. This level can be measured directly on a drop of blood with a portable hematofluorometer, and it is a useful screening test in field survey, particularly in children [38].

Reticulocyte hemoglobin content (RHC): This indicates the amount of iron that is available for erythropoiesis in the previous 3-4 days, and is an early, sensitive indicator

Table 4. Hemoglobin levels to diagnosis anemia specified by the World Health Organization [36]

\begin{tabular}{|c|c|c|c|c|}
\hline \multirow{2}{*}{ Age or gender group } & \multicolumn{4}{|c|}{ Hemoglobin (g/dL) } \\
\hline & Non-anemia & Mild-anemia & Moderate-anemia & Severe-anemia \\
\hline Men & 13 or higher & $11-12.9$ & $8-10.9$ & Lower than 8 \\
\hline \multicolumn{5}{|l|}{ Women } \\
\hline Non-pregnancy & 12 or higher & $11-11.9$ & $8-10.9$ & Lower than 8 \\
\hline Pregnancy & 11 or higher & $10-10.9$ & $7-9.9$ & Lower than 7 \\
\hline \multicolumn{5}{|l|}{ Children } \\
\hline 6-59 months & 11 or higher & $10-10.9$ & $7-9.9$ & Lower than 7 \\
\hline 5-11 years & 11.5 or higher & $11-11.4$ & $8-10.9$ & Lower than 8 \\
\hline $12-14$ years & 12 or higher & $11-11.9$ & $8-10.9$ & Lower than 8 \\
\hline
\end{tabular}


of ID that is not affected by inflammation [31]. Also, its rapid change is useful for evaluating the response of iron treatment.

Hypochromic red cells (\% HRC): The level of HRC reflects recent iron reduction [35]. It is the most sensitive marker of ID in patients with chronic kidney disease, in which the cutoff value is $6 \%$ [13].

\section{Therapy}

The purpose of treatment of IDA, is to normalize hemoglobin concentration and replenish iron stores to improve symptoms, quality of life, and the prognosis of chronic diseases [13]. The treatment of IDA is iron supply. Treatment should always begin when a precise laboratory diagnosis is established. In addition, appropriate nutritional recommendations and correction of ID-causing disease are necessary. For example, eradiation of $H$. pylori infection and management of gastrointestinal blood loss should be considered for treatment of IDA. The WHO recommends supplementation of iron to prevent ID or IDA in communities with an anemia prevalence $\geq 40 \%[41]$.

\section{1) Oral iron therapy}

For a majority of patients with IDA, oral iron supplementation is effective and is associated with easy administration and low cost. Ferrous sulfate, ferrous fumarate, ferrous gluconate, ferrous ascorbate, ferrous lactate, ferrous succinate, or ferrous glycine sulfate are used as oral iron supplements. A daily total dose of $3-6 \mathrm{mg} / \mathrm{kg}$ of elemental iron in 1 or 2 doses is adequate, in which the maximum dose is $150-200 \mathrm{mg}$ of elemental iron daily. For example, ferrous sulfate is $20 \%$ elemental iron by weight and is ideally given between meals with vitamin C-containing juice [34]. More effective iron absorption and the rapid recovery of hemoglobin levels in IDA patients with low hepcidin levels [3]. The total iron consumption period is about 3 to 6 months, since after the hemoglobin is normalized, it is necessary to take iron supplement for 8 weeks for repletion of iron stores in the body [2]. However, side effects are reported up to $30-70 \%$ of patients, which limits long term use of oral iron [ 42 , 43]. Epigastic discomfort, nausea, diarrhea, and constipation are common complaints, but are not severe. Oral iron supplements are also associated with dark stools, but this effect is not harmful, and does not cause false positive results in occult blood tests [3,13]. If treatment fails, the cause may include poor patient compliance with oral regimen, insufficient iron dose or duration, other underlying diseases, or the patient's condition may be refractory to treatment. A pilot study reported that measuring serum hepcidin levels may help predict response to oral iron; however, the hepcidin test is not routinely used in clinical practice [44].

\section{2) Parenteral iron therapy}

The efficacy of intravenous (IV) iron has already been demonstrated in dozens of randomized clinical trials and meta-analysis [45]. However, there remain some concerns about unfavorable safety issues including severe acute reactions (hypersensitivity reactions, anaphylaxis), long-term biologic effects of generating oxidative stress, patient susceptibility to infections, and the potential worsening the conditions chronic metabolic disorders [3,46]. Also, first line treatment with IV iron preparations in children with IDA has been debated for many years $[47,48]$. Since mid to late 1990s, newly approved safer iron formulations modified these side effects, and many studies showed IV iron formulations are safe and may be given to iron deficient individuals without fear of infection $[46,49,50]$. Table 5 summarizes the usage, dosage and brand name of IV iron used in Korea. The cost of IV iron is higher than oral iron therapy; however, the number of hospital or outpatient visits is significantly decreased. The required dose is calculated using the Ganzoni formula [51].

Total iron deficiency $(\mathrm{mg})=[\mathrm{Bwt}(\mathrm{kg}) \times($ target hemoglobin level - patient hemoglobin level) $\left.(\mathrm{g} / \mathrm{L}) \times 0.24^{*}\right]+$ iron reserves $(\mathrm{mg})$

- Bwt <35 kg: target hemoglobin level=130 g/L, iron reserves $=15 \mathrm{mg} / \mathrm{kg}$

- Bwt $\geq 35 \mathrm{~kg}$ : target hemoglobin level=150 g/L, iron reserves $=500 \mathrm{mg}$ 
Table 5. Iron preparations for intravenous use

\begin{tabular}{|c|c|c|c|}
\hline Formulation & Brand name & Dosage form & Usage and dose \\
\hline $\begin{array}{l}\text { Ferric hydroxide } \\
\text { sucrose complex }\end{array}$ & $\begin{array}{l}\text { Venostin inj. } \\
\text { Venoferrum inj. } \\
\text { Anerrum inj. } \\
\text { Ferrovin inj. } \\
\text { Ferrowell inj. } \\
\text { Femorrum inj. } \\
\text { Ferex inj. }\end{array}$ & $\begin{array}{l}2,700 \mathrm{mg} / 5 \mathrm{~mL} \\
\left(\mathrm{Fe}^{3+} 20 \mathrm{mg} / \mathrm{mL}\right)\end{array}$ & $\begin{array}{l}\text { Intravenous infusion } \\
\text {-Dilution: mix } 5 \mathrm{~mL}+100 \mathrm{~mL} \mathrm{NS} \\
\text {-Maximum dose: } 7 \mathrm{mg} / \mathrm{kg} \text { (Max Fe } 500 \mathrm{mg} \text { ), child } 3 \mathrm{mg} / \mathrm{kg} \\
\text {-Infusion rate: } 100 \mathrm{mg} \text { for } 15 \mathrm{~min} \text { or more, if maximum dose, over } \\
\text { than } 3 \mathrm{~h} 30 \mathrm{mins} \\
\text { Intravenous direct injection } \\
\text {-Maximum dose: } 10 \mathrm{~mL}\left(\mathrm{Fe}^{3+} 200 \mathrm{mg} \text { ) }\right. \\
\text {-Injection rate: slow than } 1 \mathrm{~mL} / \mathrm{min}\end{array}$ \\
\hline Iron isomaltoside & Monofer inj. & $\begin{array}{l}417 \mathrm{mg} / \mathrm{mL} \\
\left(\mathrm{Fe}^{3+} 100 \mathrm{mg} / \mathrm{mL}\right),\end{array}$ & $\begin{array}{l}\text { Intravenous infusion } \\
\text {-Dilution: mix } 2 \mathrm{~mL}+500 \mathrm{~mL} \mathrm{NS} \\
\text {-Maximum dose: } 20 \mathrm{mg} / \mathrm{kg} \text { (Max Fe } 500 \mathrm{mg} \text { ) } \\
\text {-Infusion rate: } \leq 1,000 \mathrm{mg} \text {, for } 30 \mathrm{mins}^{3+}>1,000 \mathrm{mg} \text {, for } 60 \mathrm{mins} \\
\text { Intravenous direct injection } \\
\text {-Maximum dose: } \mathrm{Fe}^{3+} 500 \mathrm{mg} \\
\text {-Injection rate: } 50 \mathrm{mg} / \mathrm{min} \\
\text {-Do not mix or } 20 \mathrm{~mL} \mathrm{NS} \mathrm{mix}\end{array}$ \\
\hline $\begin{array}{l}\text { Ferric hydroxide } \\
\text { carboxymaltose } \\
\text { complex }\end{array}$ & Ferinject inj. & $\begin{array}{l}180 \mathrm{mg} / \mathrm{mL} \\
\left(\mathrm{Fe}^{3+} 50 \mathrm{mg} / \mathrm{mL}\right)\end{array}$ & $\begin{array}{l}\text { Intravenous infusion } \\
\text {-Maximum dose: } \mathrm{Fe}^{3+} 1,000 \mathrm{mg} \\
\text {-Dilution and infusion rate } \\
2-4 \mathrm{~mL}+50 \mathrm{~mL} \mathrm{NS} \text {, No prescribed infusion rate } \\
4-10 \mathrm{~mL}+100 \mathrm{~mL} \mathrm{NS} \text {, over } 6 \text { mins } \\
10-20 \mathrm{~mL}+250 \mathrm{~mL} \mathrm{NS} \text {, over } 15 \mathrm{mins} \\
\text { (Do not mix under Fe } 2 \mathrm{mg} / \mathrm{mL} \text { dilution) } \\
\text { Intravenous direct injection } \\
\text {-Maximum dose: Fe }{ }^{3+} 1,000 \mathrm{mg} \\
\text {-Injection rate: Same as Intravenous infusion rate }\end{array}$ \\
\hline
\end{tabular}

NS, normal saline.

Table 6. Indication and contraindication for parenteral iron therapy [3,31,33]

Indication

Chronic inflammatory bowel disease (active disease or hemoglobin $<10 \mathrm{~g} / \mathrm{dL}$ ) or situations with proven malabsorption

Chronic kidney disease on hemodialysis or with ESA treatment

Iron-refractory iron deficiency anemia

Chronic heart disease (systolic, NYHA class II-IV)

Chronic bleeding with a uncorrectable etiology, where oral therapy is insufficiently effective or contraindicated

Failure to achieve correction of IDA after well-conducted oral iron substitution, in the setting of good adherence

Pregnancy (thirdtrimester and second trimester if hemoglobin $<10.5 \mathrm{~g} / \mathrm{dL}$ )

Contraindication

Presence of an active/acute infection

Personal history of drug anaphylaxis/allergy

Tractable comorbidity explaining the signs and symptoms

A desire to increase school/academic or sports performance in the absence of laboratory tests confirming IDA

NYHA, New York Heart Association; IDA, iron deficiency anemia.

\section{${ }^{*} 0.24=0.0034 \times 0.07 \times 1,000$ (Iron contest of hemoglobin $\fallingdotseq$ $0.34 \% /$ volume of blood $\fallingdotseq 7 \%$ of Bwt $/ 1,000=\mathrm{g}$ to $\mathrm{mg}$ )}

The benefits of IV iron infusion are reduction of GI side effect, bypassing of the intestinal mucosal barrier, and faster hemoglobin response. Additionally, patient compliance has little effect on the results; rather, these advantages improve compliance [52].

The indications using intravenous iron are summarized in Table 6. In general, IV iron infusion can be considered when the response, tolerability, and adherence of 
oral iron therapy are not ideal, and when faced with the need for rapid hemoglobin recovery, or in the presence of genetically induced IRIDA [31,53,54]. In addition, IV iron is essential in patients with chronic inflammatory conditions, such as heart failure or chronic kidney disease. Several studies have shown that use of IV iron in chronic heart failure (New York Heart Association class II or III) with ID significantly improves functional capacity, quality of life and symptoms, and reduces hospitalization rate up to $61 \%$ [30,55-57]. In patients with chronic kidney disease, IV iron is the recommended front line treatment in patients on dialysis [58]. Even non-dialysis-dependent patients with chronic kidney disease showed better hemoglobin response to IV iron than oral iron [59]. IV iron may also augment the response to erythropoietin therapy, or even delay the need for erythropoietin therapy [60]. Patients with inflammatory bowel disease, or with a condition with proven malabsorption require IV iron [33]. Acute inflammatory bowel disease is also emerging as an indication for IV iron use, since oral iron is not only ineffective, but can also increase local inflammation [61,62]. On the other hand, improvements in iron status with IV iron therapy have led to significantly improved quality of life in patients with inflammatory bowel disease [63]. Accordingly, IV iron is recommended as the front line treatment in patients with active or advanced disease or hemoglobin levels $\leq 10 \mathrm{~g} / \mathrm{dL}$ [58]. Additionally, recent guidelines suggest that pregnant women with IDA should use IV iron when hemoglobin levels are $<10.5 \mathrm{~g} / \mathrm{dL}$ in the $2 \mathrm{nd}$ trimester, and at any time in the 3rd trimester [64].

The transient side effects of IV iron are nausea, vomiting, pruritus, headache, myalgia, back and chest pain, which usually resolve within 48 hours [65]. Contraindications include history of drug anaphylaxis or allergy; however, severe of life threatening phenomena, such as hypersensitivity reactions, are very rare in currently used formulations. Recommendations to minimize this risk include a slow infusion rate, careful observation, and administration by trained health are personnel in facilities equipped with resuscitation [49].

\section{Iron-Refractory IDA}

IRIDA is an autosomal recessive disease caused by a mutation in TMPRSS6 [66]. This gene encodes the liver hepcidin inhibitor TMPRSS6, called matriptase-2 [19,67]. TMPRSS6 play a role in down regulating hepcidin activation by the BMP/SMAD pathway, cleaving the co-receptor HJV from hepatocyte plasma membrane (Fig. 1) [19]. In IRIDA, mutation in TMPRSS6 leading to elevated hepcidin levels, blocks iron intestinal absorption, and iron release from intestinal cell or macrophage. Subsequently, the circulating iron level is reduced, resulting in insufficient erythropoiesis.

IRIDA was first recognized in 2008 [67]. The definition of "refractory" related to IRIDA is absence of hematologic response, or an increase of $<1 \mathrm{~g}$ of hemoglobin, after 4 to 6 weeks of treatment with oral iron [68]. It usually requires parenteral, IV iron, especially when the iron needs are high, as seen in children, since the degree of anemia is more pronounced during childhood [69].

\section{IDA with Chronic Inflammatory Disease}

Conditions associated with chronic inflammation have been linked to iron deregulation. Hepcidin, which plays a key role in iron homeostasis, is affected by inflammation. Among the cytokines secreted during inflammation, interleukin (IL)-6, IL1b and IL-22 were shown to increase hepcidin expression $[31,35]$. In particular, circulating proinflammatory cytokine IL- 6 triggers hepcidin production and release. This results in increased internalization and degradation of FPN and decreased intestinal iron absorption, macrophage iron withholding, and iron restricted erythropoiesis (Fig. 1) [58]. This ultimately leads to cellular iron retention and decreased levels of circulating iron; therefore, serum ferritin is high and TFs is decreased. This may result in insufficient iron availability to meet the body's needs [70]. As a result of limited iron, patients with chronic inflammatory conditions have greater daily iron requirements to increase the levels of circulating iron compared with healthy in- 
dividuals [58].

ID with chronic inflammation disease increases the difficulty in establishing the diagnosis. In recent studies, serum ferritin less than $100 \mu \mathrm{g} / \mathrm{L}$, or TFs less than $20 \%$, was defined as the cut-off values [58]. The ratio of soluble transferrin receptor to log ferritin helps to distinguish ID form chronic inflammation disease (Table 3) [39]. Patients with coexistence of IDA and ACD more frequently have microcytes, and their anemia tends to be more severe. The prevalence of ID is estimated to 24$85 \%$ of patients with chronic kidney disease, $37-61 \%$ of patients with chronic heart failure, and $13-90 \%$ of patients with inflammatory bowel disease [58]. Since ID may exacerbate the underlying disease state and accelerate clinical deterioration in chronic inflammatory conditions, supplement of iron is essential in these conditions.

\section{Conclusion}

IDA is a common disease that occurs steadily, associated with substantial global burden. However, diagnosis and treatment of IDA is often overlooked. Since the discovery of hepcidin, understanding of iron metabolism and pathophysiology of IDA has increased, and the concept of genotype IRIDA has also been established. Indeed, continual development of effective treatment and prevention of IDA is essential.

\section{Conflict of Interest Statement}

The author has no conflict of interest to declare.

\section{References}

1. Kassebaum NJ, Jasrasaria R, Naghavi M, et al. A systematic analysis of global anemia burden from 1990 to 2010. Blood 2014;123:615-24.

2. Lee JH. Iron-deficiency anemia in children: from diagnosis to treatment. J Korean Med Assoc 2016;59:678-82.

3. Camaschella C. Iron-deficiency anemia. N Engl J Med 2015; 372:1832-43.

4. Stevens GA, Finucane MM, De-Regil LM, et al. Global, regional, and national trends in haemoglobin concentration and prevalence of total and severe anaemia in children and pregnant and non-pregnant women for 1995-2011: a systematic analysis of population-representative data. Lancet Glob Health 2013;1:e16-25.

5. GBD 2017 Disease and Injury Incidence and Prevalence Collaborators. Global, regional, and national incidence, prevalence, and years lived with disability for 354 diseases and injuries for 195 countries and territories, 1990-2017: a systematic analysis for the Global Burden of Disease Study 2017. Lancet 2018;392:1789-858.

6. Lee JO, Lee JH, Ahn S, et al. Prevalence and risk factors for iron deficiency anemia in the korean population: results of the fifth Korea National Health and Nutrition Examination Survey. J Korean Med Sci 2014;29:224-9.

7. Yoon HS. Iron deficiency anemia in childhood. J Korean Med Assoc 2011;54:725-9.

8. Suh JK, Jeon I. Basic understanding of iron metabolism. Clin Pediatr Hematol Oncol 2018;25:1-9.

9. Camaschella C. Iron and hepcidin: a story of recycling and balance. Hematology Am Soc Hematol Educ Program 2013; 2013:1-8

10. Hentze MW, Muckenthaler MU, Galy B, Camaschella C. Two to tango: regulation of mammalian iron metabolism. Cell 2010;142:24-38.

11. Pigeon C, Ilyin G, Courselaud B, et al. A new mouse liverspecific gene, encoding a protein homologous to human antimicrobial peptide hepcidin, is overexpressed during iron overload. J Biol Chem 2001;276:7811-9.

12. Nemeth E, Tuttle MS, Powelson J, et al. Hepcidin regulates cellular iron efflux by binding to ferroportin and inducing its internalization. Science 2004;306:2090-3.

13. Lopez A, Cacoub P, Macdougall IC, Peyrin-Biroulet L. Iron deficiency anaemia. Lancet 2016;387:907-16.

14. Babitt JL, Huang FW, Wrighting DM, et al. Bone morphogenetic protein signaling by hemojuvelin regulates hepcidin expression. Nat Genet 2006;38:531-9.

15. Andriopoulos B Jr, Corradini E, Xia Y, et al. BMP6 is a key endogenous regulator of hepcidin expression and iron metabolism. Nat Genet 2009;41:482-7.

16. Camaschella C, Nai A, Silvestri L. Iron metabolism and iron disorders revisited in the hepcidin era. Haematologica 2020; 105:260-72.

17. D'Angelo G. Role of hepcidin in the pathophysiology and diagnosis of anemia. Blood Res 2013;48:10-5.

18. Zhang AS, Yang F, Wang J, Tsukamoto H, Enns CA. Hemojuvelinneogenin interaction is required for bone morphogenic protein-4-induced hepcidin expression. J Biol Chem 2009;284: 22580-9.

19. Silvestri L, Pagani A, Nai A, De Domenico I, Kaplan J, Camaschella C. The serine protease matriptase-2 (TMPRSS6) inhibits hepcidin activation by cleaving membrane hemojuvelin. Cell Metab 2008;8:502-11.

20. Pasricha SR, Lim PJ, Duarte TL, et al. Hepcidin is regulated by promoter-associated histone acetylation and HDAC3. Nat Commun 2017;8:403.

21. Kautz L, Jung G, Valore EV, Rivella S, Nemeth E, Ganz T. Identification of erythroferrone as an erythroid regulator of iron 
metabolism. Nat Genet 2014;46:678-84.

22. Korea Centers for Disease Control and Prevention. Korea Health Statistics 2018 : Korea National Health and Nutrition Examination Survey (KNHANES VII-3). Cheongju, Korea: Korea Centers for Disease Control and Prevention, 2018.

23. Joo EY, Kim KY, Kim DH, Lee JE, Kim SK. Iron deficiency anemia in infants and toddlers. Blood Res 2016;51:268-73.

24. Mozaheb Z, Khayami M, Sayadpoor D. Iron balance in regular blood donors. Transfus Med Hemother 2011;38:190-4.

25. Goddard AF, James MW, McIntyre AS, Scott BB. Guidelines for the management of iron deficiency anaemia. Gut 2011; 60:1309-16.

26. Muhsen K, Cohen D. Helicobacter pylori infection and iron stores: a systematic review and meta-analysis. Helicobacter 2008;13:323-40.

27. Lozoff B, Jimenez E, Hagen J, Mollen E, Wolf AW. Poorer behavioral and developmental outcome more than 10 years after treatment for iron deficiency in infancy. Pediatrics 2000; 105:E51.

28. Munzer T, Felt B. The role of iron in pediatric restless legs syndrome and periodic limb movements in sleep. Semin Neurol 2017;37:439-45.

29. Leung W, Singh I, McWilliams S, Stockler S, Ipsiroglu OS. Iron deficiency and sleep - A scoping review. Sleep Med Rev 2020; $51: 101274$

30. Anker SD, Comin Colet J, Filippatos G, et al. Ferric carboxymaltose in patients with heart failure and iron deficiency. N Engl J Med 2009;361:2436-48.

31. Cappellini MD, Musallam KM, Taher AT. Iron deficiency anaemia revisited. J Intern Med 2020;287:153-70.

32. Baker R, Greer F. Committee on Nutrition, American Academy of Pediatrics. Clinical report: diagnosis and prevention of iron deficiency and iron-deficiency anemia in infants and young children (0-3 years of age). Pediatrics 2010;126:104050.

33. Mattiello V, Schmugge M, Hengartner H, von der Weid N, Renella R, SPOG Pediatric Hematology Working Group. Diagnosis and management of iron deficiency in children with or without anemia: consensus recommendations of the SPOG Pediatric Hematology Working Group. Eur J Pediatr 2020; 179:527-45.

34. Rothman JA. Iron-deficiency anemia. In: Kliegman RM, Geme J St, editors. Nelson textbook of pediatrics. 21st ed. Philadelphia: Elsevier, 2020;2522-6.

35. Camaschella C. New insights into iron deficiency and iron deficiency anemia. Blood Rev 2017;31:225-33.

36. World Health Organization. Haemoglobin concentrations for the diagnosis of anaemia and assessment of severity. Vitamin and Mineral Nutrition Information System. Geneva: World Health Organization, 2011.

37. Punnonen K, Irjala K, Rajamaki A. Serum transferrin receptor and its ratio to serum ferritin in the diagnosis of iron deficiency. Blood 1997:89:1052-7.

38. Zimmermann MB, Hurrell RF. Nutritional iron deficiency. Lancet 2007:370:511-20.

39. Weiss G, Goodnough LT. Anemia of chronic disease. N Engl J Med 2005;352:1011-23.
40. Girelli D, Nemeth E, Swinkels DW. Hepcidin in the diagnosis of iron disorders. Blood 2016;127:2809-13.

41. World Health Organization. Guideline daily iron supplementation in infants and children. Geneva: World Health Organization, 2016.

42. Cancelo-Hidalgo MJ, Castelo-Branco C, Palacios S, et al. Tolerability of different oral iron supplements: a systematic review. Curr Med Res Opin 2013;29:291-303.

43. Tolkien Z, Stecher L, Mander AP, Pereira DI, Powell JJ. Ferrous sulfate supplementation causes significant gastrointestinal side-effects in adults: a systematic review and meta-analysis. PLoS One 2015;10:e0117383.

44. Bregman DB, Goodnough LT. Experience with intravenous ferric carboxymaltose in patients with iron deficiency anemia. Ther Adv Hematol 2014;5:48-60.

45. Notebaert É, Chauny JM, Albert M, Fortier S, Leblanc N, Williamson DR. Shortterm benefits and risks of intravenous iron: a systematic review and meta-analysis. Transfusion 2007; 47:1905-18.

46. Avni T, Bieber A, Grossman A, Green H, Leibovici L, GafterGvili A. The safety of intravenous iron preparations: systematic review and meta-analysis. Mayo Clin Proc 2015;90:1223.

47. Auerbach M. Should intravenous iron be upfront therapy for iron deficiency anemia? Pediatr Blood Cancer 2011;56:511-2.

48. Mantadakis E. Intravenous iron: safe and underutilized in children. Pediatr Blood Cancer 2018;65:e27016.

49. Rampton D, Folkersen J, Fishbane S, et al. Hypersensitivity reactions to intravenous iron: guidance for risk minimization and management. Haematologica 2014;99:1671-6.

50. Auerbach M, Ballard H. Clinical use of intravenous iron: administration, efficacy, and safety. Hematology Am Soc Hematol Educ Program 2010;2010:338-47.

51. Ganzoni AM. Intravenous iron-dextran: therapeutic and experimental possibilities. Schweiz Med Wochenschr 1970;100: 301-3.

52. Litton E, Xiao J, Ho KM. Safety and efficacy of intravenous iron therapy in reducing requirement for allogeneic blood transfusion: systematic review and meta-analysis of randomised clinical trials. BMJ 2013;347:f4822.

53. De Falco L, Sanchez M, Silvestri L, et al. Iron refractory iron deficiency anemia. Haematologica 2013;98:845-53.

54. Heeney MM, Finberg KE. Iron-refractory iron deficiency anemia (IRIDA). Hematol Oncol Clin North Am 2014;28:637-52, v.

55. Filippatos G, Farmakis D, Colet JC, et al. Intravenous ferric carboxymaltose in iron-deficient chronic heart failure patients with and without anaemia: a subanalysis of the FAIRHF trial. Eur J Heart Fail 2013;15:1267-76.

56. Ponikowski P, van Veldhuisen DJ, Comin-Colet J, et al. Beneficial effects of long-term intravenous iron therapy with ferric carboxymaltose in patients with symptomatic heart failure and iron deficiency. Eur Heart J 2015;36:657-68.

57. Jankowska EA, Tkaczyszyn M, Suchocki T, et al. Effects of intravenous iron therapy in iron-deficient patients with systolic heart failure: a meta-analysis of randomized controlled trials. Eur J Heart Fail 2016;18:786-95. 
58. Cappellini MD, Comin-Colet J, de Francisco A, et al. Iron deficiency across chronic inflammatory conditions: international expert opinion on definition, diagnosis, and management. Am J Hematol 2017;92:1068-78.

59. Qunibi WY, Martinez C, Smith M, Benjamin J, Mangione A, Roger SD. A randomized controlled trial comparing intravenous ferric carboxymaltose with oral iron for treatment of iron deficiency anaemia of non-dialysis-dependent chronic kidney disease patients. Nephrol Dial Transplant 2011;26: 1599-607.

60. Macdougall IC. Iron supplementation in nephrology and oncology: what do we have in common? Oncologist 2011;16 Suppl 3:25-34

61. Reinisch W, Chowers Y, Danese S, et al. The management of iron deficiency in inflammatory bowel disease--an online tool developed by the RAND/UCLA appropriateness method. Aliment Pharmacol Ther 2013;38:1109-18.

62. Lee T, Clavel T, Smirnov K, et al. Oral versus intravenous iron replacement therapy distinctly alters the gut microbiota and metabolome in patients with IBD. Gut 2017;66:863-71.

63. Çekiç C, İpek S, Aslan F, et al. The effect of intravenous iron treatment on quality of life in inflammatory bowel disease patients with nonanemic iron deficiency. Gastroenterol Res
Pract 2015;2015:582163.

64. Achebe MM, Gafter-Gvili A. How I treat anemia in pregnancy: iron, cobalamin, and folate. Blood 2017;129:940-9.

65. Auerbach M, Strauss W, Auerbach S, Rineer S, Bahrain H. Safety and efficacy of total dose infusion of $1,020 \mathrm{mg}$ of ferumoxytol administered over 15 min. Am J Hematol 2013;88: 944-7.

66. Finberg KE, Heeney MM, Campagna DR, et al. Mutations in TMPRSS6 cause iron-refractory iron deficiency anemia (IRIDA). Nat Genet 2008;40:569-71.

67. Du X, She E, Gelbart T, et al. The serine protease TMPRSS6 is required to sense iron deficiency. Science 2008;320:108892.

68. Hershko C, Camaschella C. How I treat unexplained refractory iron deficiency anemia. Blood 2014;123:326-33.

69. De Falco L, Silvestri L, Kannengiesser C, et al. Functional and clinical impact of novel TMPRSS6 variants in iron-refractory iron-deficiency anemia patients and genotype-phenotype studies. Hum Mutat 2014;35:1321-9.

70. Ganz T, Nemeth E. The hepcidin-ferroportin system as a therapeutic target in anemias and iron overload disorders. Hematology Am Soc Hematol Educ Program 2011;2011:53842. 